\title{
IMPLEMENTATION OF AN IMMUNISATION PROJECT FOR THE REFUGEES USING THE LOGIC MODEL
}

\author{
Lay Khim Goh, Chew Fei Sow ${ }^{1}$ and Safurah Ja'afar ${ }^{1}$ \\ ${ }^{1}$ International Medical Malaysia, 126, Jln Jalil Perkasa 19, Bukit Jalil, 57000 Kuala Lumpur, Federal Territory of Kuala \\ Lumpur, Malaysia
}

Corresponding author: Goh Lay-Khim

Email: GohLayKhim@imu.edu.my

\begin{abstract}
Refugees worldwide have been a challenge to many countries. Threats of preventable immunisable diseases amongst children that disrupt the herd immunity have been a concern as many countries lack a structured national policy to administer full vaccines to these refugees. Full immunisation coverage not only protected the refugees but also safeguarded the children of the home country. We designed a collaborative university-based community service partnership with UNHCR and International-Organisation-for-Migration, implemented a practice-integrated immunisation service initiative with the local community. This paper described the implementation process of an immunisation project for the refugees using the evaluative Logic Model. This model diagrammatically shows the relationships between the program's objectives, program activities, process indicators, outcomes, and resources used. It applies to program planning, operation, evaluation and address questions for decision making. The aim was to provide refugees' children below 18-years the complete doses of the national scheduled immunisation. The immunisation was given in six refugees-learning-centres in a total of 31 visits. The workflow includes administering the immunisation, health education, triaging, data collection, and monitoring the children immunised. A total of 1116 children received full immunisation within a period of eighteen months. Vaccines given were Pentavalent, Hepatitis $B$, TetanusDiphtheria, and Mumps-Measles-Rubella. This project has achieved more than $80 \%$ immunisation coverage for all the vaccines except Pentavalent (<50\%). The Logic Model is useful for developing, implementing, and evaluating knowledge co-production partnerships in the context of a community delivery system in this project
\end{abstract}

Keywords: Immunisation, Refugees, Logic Model.

\section{INTRODUCTION}

Refugees worldwide have been a challenge to many countries, especially those with unprecedented numbers and overstay. A refugee is defined as someone who flees their country of origin and crosses an international frontier due to conflict, violence, or persecution. They are unwilling or unable to return based on a demonstrable threat due to their race, religion, political stance, or social status. The distinction of refugees is vital as the United Nations High Commissioner for Refugee (UNHCR) is legally bound by international law to protect and assist refugees. ${ }^{1}$ Since 1975 , UNHCR provides protection and assistance to the Malaysian Government in resettling the refugees to various countries in United States, Canada, Australia, France, New Zealand, Sweden, Finland, Denmark, and Norway. The resettling is coordinated together with the International Organisation of Migration (IOM). IOM works to ensure orderly and humane management of migration. It promotes international cooperation on migration issues, finding practical solutions to migration problems, and provides humanitarian assistance to migrants in need, refugees, and internally displaced people.

The number of foreigners in Malaysia increased from 1.4 million to 2.3 million from 2000-2010. 2 . This figure represented $8.2 \%$ of 28.6 million total
Malaysian population in 2010. This could probably be underestimated as it did not include many undocumented foreigners. As of May 2017, Malaysia has received about 133,725 registered refugees (Rohingya ethnic) from Myanmar. ${ }^{3}$ The health and immunisation status of urban refugees is largely unknown. ${ }^{4}$ Threats of missed preventable communicable diseases that disrupt the herd immunity have been a concern as many countries, including Malaysia, lack a structured national policy to administer vaccines to these refugees. Zipprich et al. ${ }^{5}$ reported an outbreak of measles among thirty-one resettling USA-bound refugees from Malaysia in 2011. State and local public health agencies' rapid control efforts limit this outbreak's size and prevent the spread of measles in communities with increased numbers of unimmunised persons. Since then, $\mathrm{CDC}^{4}$ imposed strict policy for importation in this refugee population travel from Malaysia to the United States.

Immunisation remains one of the most costeffective disease prevention strategies, averting millions of childhood illnesses and deaths yearly ${ }^{6}$ Literature recommended that receiving recommended childhood immunisations on the schedule is the best way to prevent the occurrence and spread of vaccine-preventable diseases among these refugees and disrupt the herd immunity of the community they settled 
$\mathrm{in}^{7,8}$. Herd immunity occurs when a sufficient portion of the population is immune to a specific disease, thereby protecting individuals who have not developed an immunity. ${ }^{9}$ The benefits of herd immunity apply to various segments of the society; children too young to be immunised, immunosuppressed patients, the elderly, people with no access to immunisation, or those remain unimmunised by choice. The degree of herd immunity necessary to prevent an outbreak varies by disease. Any disruption of these refugees' immunisation services and mobility into the new community disrupts the herd immunity, which may increase the number of susceptible individuals and the likelihood of outbreaks of vaccine-preventable diseases in the new community. ${ }^{10}$

\section{Problem statement}

Many humanitarian organisations offer and administer vaccines. However, often they are not conducted in a comprehensive approach to ensure full coverage and completing all doses. They are commonly provided as ad hoc through "one-off" campaigns. The challenges of incomplete or noncontinuous immunisation were mostly attributed to (1) budget constraint, (2) belief or culture toward immunisation, (3) tracking difficulty, and (4) illegal immigrant.

\section{Budget constraint}

While the UNHCR recognises the refugees, Malaysia is not a signatory to the Convention Relating to the Status of Refugees (1951). The Protocol Relating to the Status of Refugees (1967) means all refugees are viewed as illegal migrants awaiting resettlement in a third country. Malaysia does not extend protection, job opportunities, or education to them. That includes funding for immunisation. According to Mahimbo et al. ${ }^{11}$, the absence of a national funding model and lack of discreet financing of vaccines for refuges act as a significant impediment to catch-up immunisation delivery. Leeds et al. ${ }^{8}$ identified that fleeing war and poverty contributed to the barrier to catchup immunisation. The out-of-pocket costs discouraged refugee parents from immunising their children. ${ }^{12}$

\section{Believe or culture toward immunisation}

Several authors expressed that parents had conflicting opinions on immunisation. A long list of reasons includes bad experience of severe adverse reaction after immunisation, concern about safety, side effect and effectiveness of vaccine, preferred use of complementary medicine for the children, inadequate knowledge and awareness of immunisation, not trusting public immunisation service, weak public health education program, religious persecution, disparities in health and access to care by race and ethnicity as well as language and cultural barriers, certain beliefs about the vaccine among specific ethnic and racial groups that deter caregivers from initiating immunisation from their children. ${ }^{8,12,13}$

\section{Tracking difficulty}

Mahimbo et al. ${ }^{11}$ identified that the immunisation program lack clarity regarding who is responsible for ensuring completion of catch-up immunisation and inadequate referral pathways. To ensure the continuity of immunisation, the program requires communication between providers, notably the refugees' transition from refugee health service to primary care for mid-catch-up. Besides that, the complexities associated with the planning and implementation and completion of catch-up plans for refugees and lack of direction from the Government regarding available policies and guidelines were conveyed as a contributory factor for the existing gaps in immunisation service delivery to refugees.

\section{Illegal immigrant}

Forced migrations may result in incomplete immunisation of routine immunisation. ${ }^{10}$ Illegal immigrants or undocumented immigrants cannot access immunisation due to legislation issues and the fear of being deported.

\section{Strategies to achieving full immunisation}

Nnadi et al. ${ }^{6}$ identified that working with other development partner agencies may be the key to gaining trust, interest, and access to the community. Community engagement is a crucial element of successful vaccine delivery as the Community-Leader plays a role as information sharing with communities, building community mobilisation networks, and build trust between the community and the immunisation program. Grigg-Saito et al. ${ }^{14}$ provide a case example of community health promotion and outreach that builds on the Cambodian community's strengths. They highlight involving elders in organising events, avoiding reliance on literacy, integrating health promotion with socialisation, strong religious involvement, developing transportation alternatives, and utilising local Khmer language media. This project involved the refugee learning centers' person-in-charge in disseminating information, overcoming the language barrier, and coordinate immunisation schedules. Opportunities for defaulter tracing activities and catch up campaigns should also be in place for those who may have missed routine immunisations. ${ }^{10}$

Cognisance of the incomplete immunisation or no immunisation status of the refugee's children and its importance of ensuring herd immunity, IMU designed a collaborative university-based research partnership, develop and implement a practice-integrated immunisation service initiative with the local community. 


\section{Evaluation framework}

In the accountability era, what gets measured gets done. ${ }^{15}$ By measuring results, we differentiate success from failure, reward success, learn from success, correct failure, avoid rewarding failure, and win support with the result demonstrated. Using a structured model allowed the application of systematic methods to address questions about project operations and results. ${ }^{16}$ By applying a structured framework for project planning, implementation, and evaluation, it allows a "systematic collection and analysis of information related to the design, implementation, and outcomes of a project, for monitoring and improving the quality and effectiveness of the program." 16 ACGME ${ }^{17}$ and $\mathrm{LCME}^{18}$ advocate evaluation of the program as part of medical education accreditation organisations. The evaluation allows accountability to funding resources, helps make judgment and decision with the evidence synthesised, engage stakeholders, calibrates implementation, and interprets results.

A program is fundamentally about change, and the focus of change directs that program evaluation should look for both intended and unintended changes associated with the program. ${ }^{19}$ An evaluation model must be designed to provide information back to guide the program's continuing development, making the program evaluation an integral part of the change process. The evaluation model can be a simple linear perspective when assessing program elements and outcomes or complex systems with non-linear relationships between their elements and program-related changes. The non-linear relationship can be complex and extensive, and measurement may be multifaceted. The type of evaluation can be pure need assessment, process evaluation, outcome evaluation, or a combination of any of the three types. An evaluation program can start during the development phase by setting the objectives and problem statement, determine the desired results, define the behaviours, knowledge, skills, attitudes that are necessary to achieve the outcome. ${ }^{16}$

A thoughtful selection of a specific evaluation model is paramount. Each evaluation model has its strengths and weaknesses, and selection is based on the project's needs. Here we described our project's planning and implantation using the Logic Model. ${ }^{4}$ The Logic Model was used to help design a collaborative program ready for an evaluation. It diagrammatically shows the relationships between the program's objectives, program activities, process indicators, outcomes, and resources. Logic, in this sense, refers to the relationship between elements and between an element and the whole. It is focused on the change process and the system within which the project innovation is embedded. ${ }^{20}$ The Logic Model is unlike the Kirkpatrick Model ${ }^{21}$, which focuses on program outcome, or the CIPP Model ${ }^{22,}$ which focuses on program improvement rather than proving something about the program. Logic Model ${ }^{20}$ is based on System theory ${ }^{23}$ and assumed a non-linear complexity of most educational contexts. For complex programs, the Logic Model $^{20}$ can be expanded to multiple tiers. Even though Logic Model ${ }^{20}$ is less wholesome than CIPP Model $^{22}$, which assumed the Complexity theory ${ }^{24}$, the Logic Model's structural simplicity might simplify the non-linear complexity. Complexity theory and complexity science attempt to embrace the richness and diversity of systems in which ambiguity and uncertainty are expected is a much difficult model to follow. This may be challenging for stakeholders to monitor.

Kirkpatrick Model ${ }^{21}$ does not consider the intervening variables that affect the program or the relationships between essential program elements and its context ${ }^{25}$. While the Logic Model considers the elements surrounding the program's context, the relationship between those elements and the program's social, cultural, and political context related to the planned program. Kirkpatrick Model ${ }^{21}$ by itself is unlikely to guide educators into a full evaluation of their educational program ${ }^{26}$ or provide data to illuminate why a program works. Though the CIPP Model is useful both during the planning phases of a new project and retrospective evaluation of a completed program, multiple data collection methods are required to complete the evaluation. Each data set must be analysed with methods appropriate to the data and the evaluation questions being addressed.

Logic Model is useful for stakeholders to reach shared understandings of the program activities so that desired outcomes are more likely to happen. It gives clarity and guidance to the ProjectCoordinator of their role, allows their contribution and input into the project and justification for the budget. The model leverage the power of partnerships. It allows stakeholders to make changes based on consensus and a logical process rather than on personalities, politics, or ideology. The clarity of analysis from building the model becomes a vital part of the program's overall success by keeping stakeholders focused on outcomes.

\section{METHODS}

This program involves the collaboration of the International Medical University (IMU) with UNHCR and the IOM. It implemented a community service project using IMU's existing servicelearning program. Unlike many humanitarian organisations that provide an ad hoc immunisation approach, this project targeted full immunisation coverage to the Rohingya refugee children from Myanmar in a few government-designated refugee communities known for their incomplete or nonimmunised status. The aim is to assure a better 
herd immunity to these refugees' children and accumulate to the national coverage and protection of children in Malaysia. The project was initiated in January 2017 and completed in April 2019 (two years and four months). The funding is from the IMU-Care service-learning program and UNHCR. Figure 1 shows our implementation road map of the immunisation project. The objective is to fully immunise the targeted children with all the relevant doses, deliberated with the collaborators.
We used the Logic Model to create a flowchart (Figure 1) that depicts program components to illustrate how a program is supposed to work. The components of the Logic Model are (1)Situation, (2)Input, (3)Activities, (4)Audience, (5)Output, and (6)Outcome; supplementary components of Logic Model are Assumption and External Factors. By depicting the sequence and logic of inputs, outputs, and outcomes, Logic Models ensure that the necessary data are collected to make credible causality statements.

Figure 1: Logic Model

\begin{tabular}{|c|c|c|c|c|c|}
\hline $\begin{array}{c}\text { SITUATIO } \\
\mathrm{N}\end{array}$ & INPUTS & $\begin{array}{c}\text { ACTIVITI } \\
\text { FS }\end{array}$ & AUDIENCE & OUTPUTS & OUTCOMES \\
\hline $\begin{array}{l}\text { The } \\
\text { situational } \\
\text { context that } \\
\text { lead to the } \\
\text { creation of } \\
\text { the program } \\
\text { Many } \\
\text { displaced } \\
\text { persons who } \\
\text { were transit } \\
\text { placement in } \\
\text { Malaysia were } \\
\text { stuck from } \\
\text { relocation. } \\
\text { Threats of } \\
\text { preventable } \\
\text { communicable } \\
\text { diseases which } \\
\text { disrupt the } \\
\text { herd immunity }\end{array}$ & 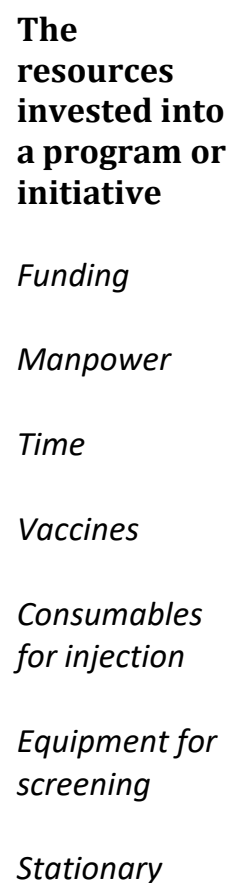 & $\begin{array}{l}\begin{array}{l}\text { Activities or } \\
\text { intervention } \\
\mathbf{s} \text { that will be } \\
\text { carried out } \\
\text { as part of the } \\
\text { program }\end{array} \\
\text { Registration/re } \\
\text { cord of data } \\
\text { Screening } \\
\text { candidates' } \\
\text { fitness for } \\
\text { immunisation } \\
\text { Immunised } \\
\text { participates }\end{array}$ & $\begin{array}{l}\text { Whom the } \\
\text { program is } \\
\text { targeting. } \\
\text { Programs } \\
\text { may target } \\
\text { specific } \\
\text { groups } \\
\text { Refugee } \\
\text { children age } 1 \\
\text { to } 18 \text { years- } \\
\text { old }\end{array}$ & $\begin{array}{l}\begin{array}{l}\text { Products } \\
\text { that are } \\
\text { produced } \\
\text { from } \\
\text { program } \\
\text { activities or } \\
\text { intervention } \\
\mathbf{s}\end{array} \\
\text { Refugee } \\
\text { children } \\
\text { received full } \\
\text { coverage of } \\
\text { immunisation }\end{array}$ & $\begin{array}{l}\text { The changes } \\
\text { expected to } \\
\text { result from } \\
\text { the program } \\
\text { Preserved herd } \\
\text { immunity } \\
\text { Contain the } \\
\text { spread of } \\
\text { communicable } \\
\text { diseases }\end{array}$ \\
\hline
\end{tabular}

\section{ASSUMPTIONS}

Underlying theories and beliefs about the program and its context which can influence the development of a program and which activities are implemented

- UNHCR and IMU-Cares-Department consistent in funding this project

- Collaboration with UNHCR and school leader increase the parents' confidence toward vaccination

- $\quad$ Collaborate with the centres where they bridged communication and build rapport and trust

- All parents able to bring their children for full immunisation

\section{EXTERNAL FACTORS}

Factors that impact the program but are beyond the control of program planners and overseers. Factors may be positive or negative and are likely to influence program success

- Unexpected changes in funding to purchase vaccine, equipment and consumables

- The negative believe or culture influence the refugee parents refused vaccination for their children

- Difficult to keep track for full immunisation, e.g. transferred

- Unforeseen conditions that not fit for vaccination, e.g. sick

- Illegal immigrant afraid to show up for vaccination

- $\quad$ Language barrier to communicate with parents and participants

- Sudden change of policy on refugee resettlement in the USA 
partnership processes included project team meetings, organisational meetings, and one-onone discussions to provide shared learning and problem-solving platforms. Decision-making responsibility was shared between the university staff, the local organisation, and the research team. The organisation line-up includes researchers, stakeholders such as executive-level project sponsor, mid-level manager, local champions who continuously communicate to discuss relevant technical, policy, and processes, with the accumulation of knowledge. The partnership's short-term outcomes were discussed, including how the partnership will affect the current research team's experience and future collaborative initiatives

Figure 2: Interplay of all stakeholders

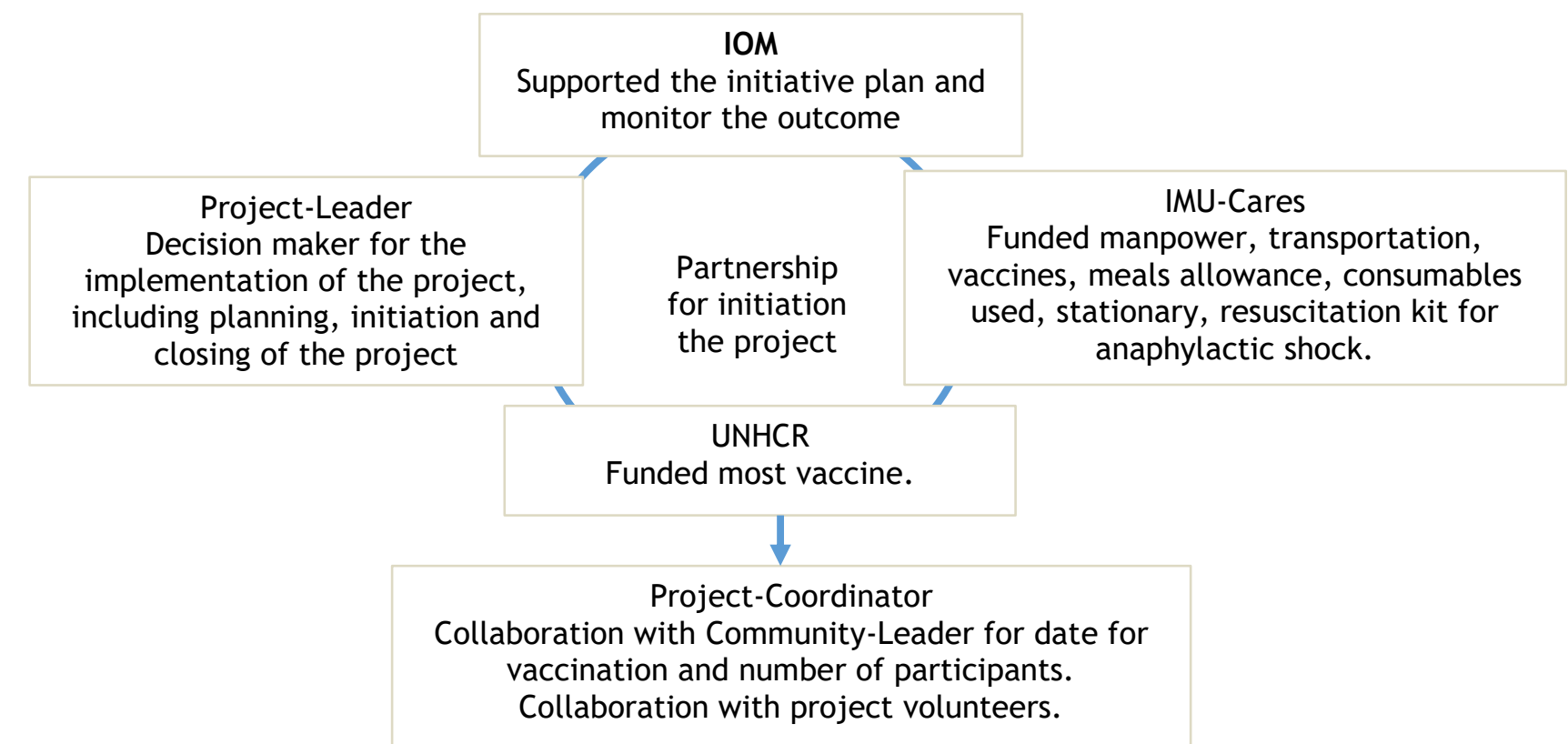

Community-Leader

Collaboration between the ProjectCoordinator and refugee parents for the project, such as communicate date for vaccination, venue arrangement, translator, and assist in taking consent for vaccination
Project volunteers

Medical doctors: Taking consent and screening fitness for vaccination

Doctors/nurses: Administration of vaccines Administrators: Register and data management

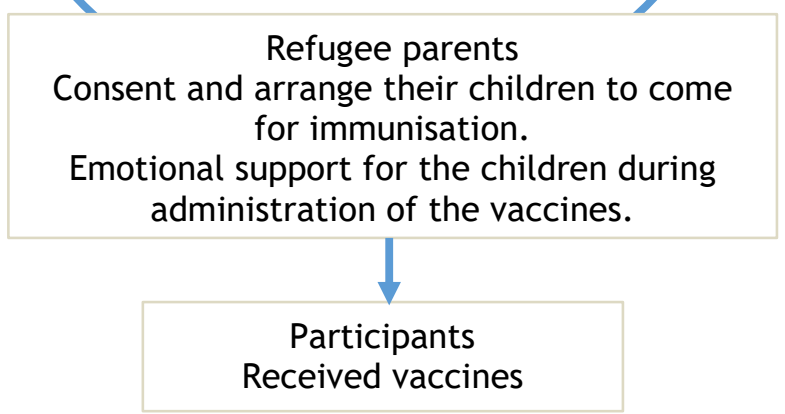

Challenges that include funding, materials, human resources, logistics, and location scheduling were discussed, weaning out obstacles and reaching mutual consensus on strategies and action plans. Six refugee-learning-centres were agreed upon. Implementation activities were structured into two phases. Phase One was launched in January 2017, where the vaccines Mumps, Measles, and Rubella (MMR) were given to 483 refugee children between two to fourteen years old in four refugee-learning-centres. According to the Malaysian National Immunisation
Schedule 28 , two MMR doses are to be given three months apart. Phase Two was launched in February 2018, covered children from one to eighteen years in five refugee-learning-centres selected, including the four refugee-learningcentres which have already been given MMR the year before. The immunisation given was Pentavalent (Penta), Hepatitis B (Hep B), Diphtheria, and Tetanus Toxoid (DT). All vaccines were given complete doses according to the schedule recommended by the Malaysian National Immunisation Schedule. ${ }^{28}$ Penta was given to those below six years old; the gap between the 
first dose and the second dose was one month, and the gap between the second and third dose was two months. Hep B and DT were for those refugees aged seven years old and above. For Hep $B$, the gap between the first dose to the second and third dose was one month and six months. The gap for DT between the first dose to the second and third dose was one month and three months. Table 1 below illustrated the schedule for Penta, Hep B, and DT.

Table 1: Schedule for the immunisation

\begin{tabular}{lllllll}
\hline Vaccine & $\mathbf{0}$ months & $\mathbf{1}^{\text {st }}$ months & $\mathbf{2}^{\text {nd }}$ months & $\mathbf{3}^{\text {rd }}$ months & $\mathbf{6}^{\text {th }}$ months & $\mathbf{1 8}^{\text {th }}$ months \\
\hline Penta & $1^{\text {st }}$ dose & $2^{\text {nd }}$ dose & & $3^{\text {rd }}$ dose & \multirow{2}{*}{ Booster dose } \\
Hep B & $1^{\text {st }}$ dose & $2^{\text {nd }}$ dose & & & \\
DT. & $1^{\text {st }}$ dose & $2^{\text {nd }}$ dose & $3^{\text {rd }}$ dose & & \\
MMR & $1^{\text {st }}$ dose & & & & & \\
\end{tabular}

The immunisation was given in these six refugeelearning-centres in a total of 31 visits. This project's participants were formed from various disciplines, including doctors and nurses, and various departments. The corporate staff from the Marketing Department, Skill Centre, and Academic Service also participated in these activities as volunteers. The tasks listed in Figure 2 , including administering the immunisation, health education, triaging, checking and recording entries, monitoring, and observation of children immunised. The number of volunteers ranges from 4 to 23 , with a mean of 10 volunteers per visit.

The "Activities" in the Logic Model guide the flow of implementation. It helps to synchronise and calibrate the understanding of the volunteers' role in implementing this project. Table 2 illustrated the workflow of the project from preparation to completion of the immunisation.

Table 2: Workflow of immunisation project

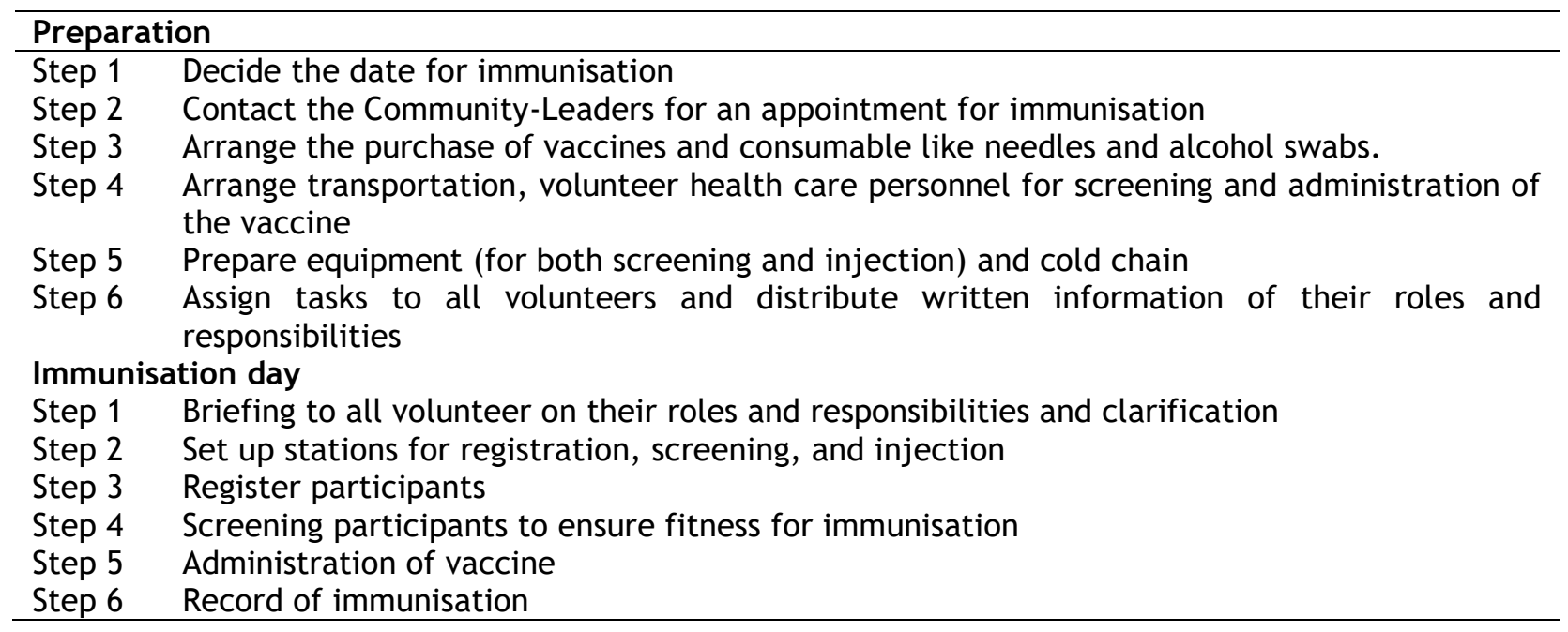

\section{Validation of the Logic Model}

The model was validated using inter-rater agreement between the researchers through semi-structured interviews with the Project-
Leader and the Project-Coordinator. The researchers attempted to identify the ProjectLeader's and the Project-Coordinator's responses in the main component and the complementary components to validate the selected Logic Model. Table 3 illustrated the list of guided questions modified from Damasceno et al. ${ }^{29}$ 
Table 3: Modified list of guided questions for validation of the Logic Model

\begin{tabular}{ll}
\hline Logic Model elements & Interview questions \\
\hline $\begin{array}{l}\text { Situation } \\
\text { Inputs }\end{array}$ & $\begin{array}{l}\text { Is there any indicator of the immunisation project needed? } \\
\text { Were the financial, material, and human resources made available for the } \\
\text { project appropriate to the needs? } \\
\text { Did the implementation strategies help to reach the project objectives? }\end{array}$ \\
$\begin{array}{l}\text { Activities } \\
\begin{array}{l}\text { Outience } \\
\text { Outcomes }\end{array}\end{array}$ & $\begin{array}{l}\text { Does the targeted group of refugees require the immunisation? } \\
\text { Were the project objectives aligned with the proposed results? }\end{array}$ \\
& Are other outcomes expected as a consequence of the project's effects? \\
\hline
\end{tabular}

\section{RESULTS}

A total of 1116 children received full immunisation for Penta, Hep B, DT, and MMR. Table 4 shows the breakdown of the number of children who received various immunisations. 22 children received complete full doses for Penta,
329 children completed full doses of Hep B, 402 children immunised with complete full doses of DT, and 363 children received complete full doses of MMR. This project has achieved more than $80 \%$ immunisation coverage for Hep B, DT, and MMR, as shown in Table 4.

Table 4: Breakdown of number of children received various immunisations

\begin{tabular}{lllllllllllll}
\hline & \multicolumn{3}{c}{ Penta } & \multicolumn{3}{c}{ Hep B } & \multicolumn{3}{c}{ TD } & \multicolumn{2}{c}{ MMR } \\
\hline The six & 1st & 2nd & 3rd & Booster & 1st & 2nd & 3rd & 1st & 2nd & 3rd & 1st & 2nd \\
Centres & dose & dose & dose & dose & dose & dose & dose & dose & dose & dose & dose & dose \\
ACR & 25 & 17 & 16 & 13 & 156 & 153 & 92 & 132 & 110 & 99 & 220 & 215 \\
ULC & 4 & 3 & 2 & 0 & 64 & 58 & 36 & 47 & 42 & 37 & 50 & 27 \\
Lautu & 2 & 2 & 2 & 1 & 32 & 28 & 16 & 28 & 28 & 26 & - & - \\
LFLC & 15 & 10 & 9 & 7 & 47 & 36 & 22 & 28 & 26 & 25 & 76 & 69 \\
ROH & 22 & 11 & 5 & 1 & 49 & 34 & 18 & 32 & 24 & 22 & 56 & 52 \\
DFC & - & - & - & - & - & 186 & 145 & 234 & 211 & 193 & - & - \\
Total & 68 & 43 & 34 & 22 & 348 & 495 & 329 & 501 & 441 & 402 & 402 & 363 \\
Coverage & & $63 \%$ & $50 \%$ & $32 \%$ & & & $95 \%$ & & & $80 \%$ & & $90 \%$ \\
\hline
\end{tabular}

\section{DISCUSSION}

It is a common finding that the immunisation status of refugees in many countries is low. Watts et al. ${ }^{7}$ reported that only $39 \%$ of a predominantly Vietnamese refugee population had evidence of adequate immunisation at their initial visit; Roberton et al. ${ }^{27}$ reported that only $24.5 \%$ of Syrian refugee children in Jordan and $12.5 \%$ in Lebanon were fully immunised through routine immunisation services, while Berman et al. ${ }^{12}$ reported that only $10 \%$ of the refugees received three doses of Hepatitis B virus immunisation. Low coverage does not assure protection from communicable diseases. In fact, it may bring about a false expectation of security. Contrarily, this immunization project covers $80 \%$ or more for Hep B, TD \& MMR.

This project acknowledged the widespread low coverage and initiated a difference by identifying the challenges of completing a full immunisation dose. Using the Logic Model, the assumptions and external factors were easily analysed, and options and solutions were offered. To achieve $80 \%$ and above coverage, the team has anticipated and overcomes those challenges mentioned under the Introduction section's Problem Statement.

\section{Budget constraint}

To ensure that the most suitable projects are chosen, project funding is a crucial strategic decision. Sub-optimal projects are financed due to unexpected circumstances that affect the budget allocation, mistakes in calculation, planning error, and strategic misrepresentation of target benefits. Van den Broucke et al. ${ }^{30}$ reported on the assessment of criteria to select projects for funding in the EU health programme. The key element in selecting the most valuable projects in assuring the EU Health Programme's quality is the evaluation process according to quality standards. The Logic Model helps in the strategic planning of funding from the stakeholders. It illustrates the stakeholders' roles for accountability. The supplementary component of the External Factor helps anticipate factors beyond the control of 
program planners that could impact the program. Based on this, contingency plans could be drawn.

\section{Belief or culture toward immunisation}

Community engagement is a critical element of successful vaccine delivery as the CommunityLeader plays a role as information sharing with communities, building community mobilisation networks, and build trust between the community and the immunisation program. The ProjectLeader works closely with the refugee-learningcentre's Community-Leaders. They disseminate information regarding the importance of immunisation, translated in their language for parent consent, and arranged the immunisation schedule; either before or after the classes. If the children could not receive immunisation due to sickness, transportation was arranged by the Community-Leaders for its replacement when the children have recuperated. This pre-planning is vital to manage funds and scheduling. Working with well-developed partner agencies ensures the delivery point for the immunisation. It is the key to gaining trust, interest, access to the community $^{6}$ as well as organise defaulter tracing activities and catch up campaigns for those who may have missed routine immunisations ${ }^{10}$. The success rate of full immunisation largely contributed to the Community-Leaders' commitment to encouraging the refugees to trust this project.

\section{Tracking difficulty}

The purpose of the refugee-learning-centres established by various Non-GovernmentOrganisation is to provide education to refugee children between 6 to 18 years old as the Malaysian Government does not support refugees in the National schooling system. The full dose immunisation was achieved as the vaccines were given to the registered students in the refugeelearning-centres during their schooling days. However, the full dose immunisation for Penta was much lower (32\%) because the vaccine was given to those registered students' siblings. There is difficulty in tracing the younger children who are not registered with the refugee-learningcentres, and some of the parents are unwilling to continue the vaccine schedule. Additionally, many refugee families migrated to the other countries within 18 months needed for complete immunisation. Though Literature has explored the reasons behind parental refusal of vaccines ${ }^{13}$, future studies could be conducted to explore our local context with these groups of refugees. In this program, we have to improvise our plan when several children did not attend the immunisation due to sickness. A quick revision of the plan was made on arranging replacement immunisation after they recovered in our university.

\section{Illegal immigrant}

This project did not face illegal immigrant issues, as the participants were registered with the refugee-learning-centre.

\section{Others challenges}

The real effects of intervention actions could differ from the intended outcomes. Specific actions might even make problems worse. In this project, the worries of side-effect (fever, rash, etc.) or worse, an unexpected anaphylactic shock which is life-threatening. Therefore, it is vital to monitor the plan and focused on the real-life experiences of community members

No matter how logical the Logic Model seems, there is always a danger that it will not be accurate as we may not comprehend the logic of change until after the implementation. Establishing the appropriate boundaries of a Logic Model can be a challenge. There is often tension between focusing on the program and situating that effort within its broader context. On a purely practical level based on this example, logic modelling can be time-consuming and demand a high degree of specificity. Indeed, the Logic Models can be complicated to create, but the process of creating them, and the product, will yield many benefits throughout an initiative.

Logic Model provides a structured step-by-step approach to the implementation. It prepared the team to have alternative solutions and synchronise the execution to ensure the objectives are met. Logic Models enhance learning by integrating research findings and practice wisdom. Most initiatives are founded on assumptions about the behaviours and conditions that need to change and how they are subject to intervention. Project-leaders can structure the effect seen into short-term or immediate effects (80\% full coverage), mid-term or intermediate effects (fewer children are sick), and long-term or ultimate effect (herd immunity).

\section{Limitation}

The validation of the Logic Model was done only with the Project-Leader and Project-Coordinator. Even though UNHCR and IOM were not included in the validation process, the project's implementation was discussed with both organisations, and no issue was raised.

\section{CONCLUSION}

The Logic Model is useful for planning, implementation, and evaluation of a project. This model is a validated tool by the CDC, hence gives accountability to the Project Coordinators. Logic 
Model focuses on the evaluation of the process rather than the outcome. This formative assessment allows the flexibility and changes within the project. However, further study needs a framework that measures the outcome that could be integrated into the project's summative evaluation. One of the areas that can be measured could focus on the impact of this project quantitatively. Data collection on communicable diseases among this community can be collected to compare the period before and after the immunisation, for that immunisation that was more or less than the targeted $80 \%$ coverage. Future studies could qualitatively explore the impact on the participants and the impact of service-learning on the faculty

\section{REFERENCES}

1. Ryan J \& Childs D. Refugees and internally displaced people. In: Ryan J, Mahoney PF, Greaves I, Bowyer G, eds. Conflict and catastrophe medicine. London, UK: Springer 2002.

2. Rahman NA, Sivasampu S, Noh KM \& Khoo EM. Health profiles of foreigners attending primary care clinics in Malaysia. Malysia, BMC Health Serv Res. 2016;16:197.

3. Nokman, FS. More than 150,000 UNHCRregistered refugees, asylum-seekers in Malaysia. 2017. [Cited 2020 February 10]. Available from New Straits Times Online: https://www.nst.com.my/news/nation/ 2017/07/260905/more-150000-unhcrregistered-refugees-asylum-seekersmalaysia.

4. CDC. Program performance and evaluation office, Logic Model. 2018. [cited on 2020 Jan 15]. Available from: https://www.cdc.gov/eval/logicmodels/ index.htm.

5. Zipprich J, Harriman K, Talarico J, Edwards C. Measles among U.S.bound refugees from Malaysia - California, Maryland, North Carolina, and Wisconsin, August-September 2011. Mortality and Morbidity Weekly report Prev Chronic Dis, 2011;60(37):1281.

6. Nnadi C, Etsano A, Uba B, Ohuabunwo C, Melton M, Nganda G. Approaches to immunisation among populations in areas of conflict. J Infect Dis. 2017;216(1):1-10.

7. Watts D, Friedman JF, Viver PM, Tompkins CEA \& Alario AJ. Immunisation status of refugee children after resettlement. Med \& Health. 2011;94(10):290-293.
8. Leeds $M$ \& Muscoplat $M H$. Timelines of receipt of early childhood immunisations among children of Immigrants-Minnesota, 2016. MMWR. 2017;66 (42):1125-1129.

9. Meissner HC. Why is herd immunity so important? J. Pediatr. 2015;36(5):14.

10. Lam E, McCarthy A \& Brennan M. Vaccinepreventable disease in humanitarian emergencies among refugee and internally-displaced populations. Hum Vaccines Immunother. 2015;11(11):26272636.

11. Mahimbo A, Seale $H$, Smith $M$ \& Heywood A. Challenges in immunisation service delivery for refugees in Australia: A health system perspective. Vaccine. 2017;35: 5148-5155.

12. Berman RS, Smock L, Bair-Merritt MH, Cochran J \& Geltman PL. Giving it our best shot? Human Papillomavirus and Hepatitis $B$ Virus immunisation among refugees, Massachusetts, 2011-2013. Prev Chronic Dis. 2017;14 (E50):1-8.

13. Giambi C, Fabiani M, D'Ancona F, Ferrara L, Fiacchini D, Gallo T. Parental vaccine hesitancy in Italy-result from a national survey. Vaccine. 2018;36:779-787.

14. Grigg-Saito D, Och S, Liang S, Toof R and Silka L. Building on the Strengths of a Cambodian Refugee Community Through Community-Based Outreach. Health Promotion Practice. 2008;9(4):415-425. DOI: $10.1177 / 1524839906292176$

15. Osborne D, \& Gaebler T. Re-inventing government. New York, NY: Penguin; 1992.

16. Wholey JS, Hatry HP, Newcomer KE, eds. Handbook of practical program evaluation. 3rd ed. San Francisco, CA: Jossey-Bass; 2013.

17. ACGME. Glossary of terms. 2018 [cited 2020 January 31]. Available from : https://www.acgme.org/Portals/0/PDFs /ab_ACGMEglossary.pdf.

18. LCME (Liason committee on medical education). Functions and structure of a medical school. Standards for accreditation of medical education programs leading to the MD degree. Washington, DC: Liaison Committee on Medical Education. 2016. [cited February 2020, February 02]. Available from: http://www.lcme.org/standard.htm. 
19. Frye AW \& Hemmer PA. Program evaluation models and related theories: AMEE Guide No. 67. Medical Teacher. 2012; 34: e288-e299.

20. Frechtling J. Logic modelling methods in program evaluation. San Francisco, CA: John Wiley \& Sons; 2007.

21. Kirkpatrick D. Revisiting Kirkpatrick's four-level model. Train Dev. 1996;1:5459.

22. Stufflebeam DL, \& Shinkfield AJ. Evaluation theory, models and applications. San Francisco, CA: JosseyBass; 2007.

23. Bertalanffy L. The history and status of general systems theory. Acad Manage J. 1972;15: 407-426.

24. Mennin S. Teaching, learning, complexity and health professions education. J Int Assoc Med Sci Educat. 2010;20:162-165.

25. Holton EF, III. The flawed four-level evaluation model. Hum. Resour. Dev. Rev. 1996;7(1):5-21.

26. Bates R. A critical analysis of evaluation practice: The Kirkpatrick model and the principle of beneficence. Eval Program Plann. 2004; 27:341-347.

27. Roberton T, Weiss $W$ \& Doocy $S$. Challenges in estimating vaccine coverage in refugee and displaced population: results from household survey in Jordon and Lebanon. Vaccines. 2017;5 (22):1-12.

28. Malaysian National Immunisation Schedule. Ministry of Health Malaysia. 2020. [cited 2020, January 16]. Available from

http://www.myhealth.gov.my/en/immu nisation-schedule/.

29. Damasceno SMS, Abbad G \& Meneses PPM. Logic models and organisational training evaluations. Paideia. 2012;22(52): 217227.

30. Van den Broucke S, Dargent G, Pletschette $M$. Development and assessment of criteria to select projects for funding in the EU health programme. European Journal of Public Health. 2011; 22(4): 598-601. 